\title{
Results of a modified non-penetrating deep sclerectomy in the treatment of open angle glaucoma with or without cataract
}

This article was published in the following Dove Press journal:

Clinical Ophthalmology

25 June 2010

Number of times this article has been viewed

\author{
George Kitsos' \\ Miltiades Aspiotis' \\ Yannis Alamanos ${ }^{2}$ \\ Konstantinos Psilas' \\ 'Department of Ophthalmology, \\ Medical School, University of Ioannina, \\ loannina, Greece; ${ }^{2}$ Department \\ of Hygiene and Epidemiology, \\ Medical School, University \\ of Patras, Patras, Greece
}

Purpose: To present the technique of a modified deep sclerectomy, which we will call "reversed" deep sclerectomy (RDS) and the results and our observations of its use in patients with open angle glaucoma (OAG) and with or without cataract extraction (phacoemulsification).

Materials and methods: This prospective study included 132 eyes which underwent RDS: 37 eyes (group A) with uncontrolled OAG and 95 eyes (group B) with OAG and visually significant cataract. Mean pressure preoperatively for group A was $24.48 \pm 4.92 \mathrm{mmHg}$ and for group B was $22.99 \pm 3.00$. The mean number of antiglaucoma drugs received was $2.97 \pm 0.69$ and $2.56 \pm 0.73$ for groups A and B respectively. The RDS was performed where the deep scleral stroma is prepared in 2 parts, folded and inserted under the lateral sides of the sclerectomy, and the Schlemm's canal is opened prior to deep scleral stroma preparation. Cataract was extracted by phacoemulsification through the same scleral opening. The follow-up for group A was $22.23 \pm 10.18$ months and for group B, $25.36 \pm 10.12$ months.

Results: Postoperative intraocular pressure (IOP) $\leq 21 \mathrm{mmHg}$ was achieved for group A in $40.5 \%$ without antiglaucoma drugs and $94.6 \%$ with antiglaucoma drugs, and for group B in $66.3 \%$ and in $94.7 \%$ respectively. Mean IOP reduction was $7.02 \pm 6.35 \mathrm{mmHg}(28.67 \%, P<0.05)$ for group A and $5.26 \pm 3.72 \mathrm{mmHg}(25.06 \%, P \leq 0.05)$ for group $\mathrm{B}$, while mean drug reduction was $1.97 \pm 1.09(P<0.01)$ and $2.14 \pm 0.95(P \leq 0.01)$ respectively. 5-Fluorouracil was used in 8 eyes of group A and in 5 eyes of group B.

Conclusion: In the follow-up time during which the two groups were under study, the RDS was effective with a few complications, similar to the classic deep sclerectomy using implants or not, with the advantage, in our opinion, of a short learning curve.

Keywords: modified deep sclerectomy, cataract

\section{Introduction}

Deep sclerectomy (DS) is a non-penetrating, tunneling surgical procedure for the treatment of open angle glaucoma (OAG) cases non-responsive to drugs. Through experience acquired in time and taking into consideration the modifications suggested, ${ }^{1-10}$ DS proved to be a reliable alternative to trabeculectomy. ${ }^{8-39}$ Significant disadvantages of DS, however, is its long learning curve. ${ }^{19-22,40}$

Psilas et $\mathrm{al}^{41}$ suggested a variation of this surgical technique called "reversed" deep sclerectomy (RDS), which in their opinion eliminates, in part, the above disadvantage of the classic DS. This RDS procedure did not remove additional tissue compared to classic DS. We applied the RDS alone in patients with OAG and the combined surgery RDS and phacoemulsification in patients with OAG and cataract.
Correspondence: George Kitsos Department of Ophthalmology, University of loannina, School of Medicine, 4511 0, loannina, Greece Tel +302651042504

Fax +30 2651049709

Email gkitsos@cc.uoi.gr 
The purpose of this study is to present the surgical procedures of this technique, as well as the results and observations from its application in order to determine whether the RDS has similar effectiveness to classic DS.

\section{Materials and methods}

This is a prospective study that includes 132 eyes from 114 patients who underwent RDS (143 eyes were scheduled to undergo RDS). All the above patients were operated consecutively, after obtaining their informed consent.

Of a total of 132 eyes, 37 eyes (group A) suffered from OAG with uncontrolled intraocular pressure (IOP), despite maximum glaucoma drug therapy. The remaining 95 eyes (group B) suffered from OAG and cataract and underwent RDS, in combination with phacoemulsification (phaco). In 56 of 95 eyes $(59 \%)$ in group B, IOP preoperatively was $\leq 21 \mathrm{mmHg}$ with glaucoma drug therapy, while in the remaining 39 eyes (41\%), IOP did not respond to maximum glaucoma drug therapy. Table 1 shows the demographic characteristics of the patients of both groups, as well as the tonometry data, glaucoma drug therapy, and follow-up time. All patients were Greek Caucasians.

With the term "uncontrolled" OAG, we define cases where IOP was $>21 \mathrm{mmHg}$, measured with Goldmann applanation tonometer, despite maximum-tolerable glaucoma drug therapy, with evidence of progressing optic neuropathy and visual field defects. The criteria for the diagnosis of OAG were according to the American Academy of Ophthalmology (Glaucoma). ${ }^{42}$ Exclusion criteria included closed angle glaucoma, secondary glaucoma, previous eye surgery, previous argon-laser trabeculoplasty, and young patients less than 30 years of age. Patients with myopia or hypermetropia greater than $3 \mathrm{D}$ or astigmatism more than $1 \mathrm{D}$ that could potentially affect our measurements were also excluded. On the contrary, patients with pseudo-exfoliation glaucoma were included in the study.

Table I Demographic data of I I 4 patients (I 32 eyes)

\begin{tabular}{lll}
\hline & Group A & Group B \\
\hline Number of patients & 33 & $8 \mathrm{I}$ \\
Number of eyes & 37 & 95 \\
Males/females & $2 \mathrm{I} / \mathrm{I} 2$ & $40 / 4 \mathrm{I}$ \\
Age, years, mean (SD) & $69.70(8.42)$ & $74(7.85)$ \\
Diagnosis of POAG, n (\%) & $28(75.67)$ & $64(67.37)$ \\
Pseudoexfoliation, n (\%) & $9(24.30)$ & $31(32.60)$ \\
IOP (mmHg) (preoperatively), mean (SD) & $24.48(4.92)$ & $20.99(3.30)$ \\
Number of antiglaucoma drugs & $2.97(0.69)$ & $2.56(0.73)$ \\
(preoperatively), mean (SD) & & \\
Follow-up time (postoperatively), & $22.23(10.18)$ & $25.36(10.12)$ \\
(range I2-42 months), mean (SD) & & \\
\hline
\end{tabular}

Preoperatively, we determined the best corrected visual acuity (Snellen optotype at $5 \mathrm{~m}$ ) in all patients. We performed biomicroscopy, gonioscopy, Goldmann applanation tonometry, static perimetry with Humphrey perimeter using program 24-2 threshold (Humphrey Inc., San Leandro, California, USA), ultrasound pachymetry (Pacline; OPTICON 2000 SPA, Rome, Italy), as well as examination of the fundus and optic nerve head, when possible due to cataract presence. The central corneal thickness was within normal range (group A: $550.16 \pm 23.6 \mu \mathrm{m}$ and group B: $549.83 \pm 27.2 \mu \mathrm{m}$ ). The blood pressure for all patients of both groups was controlled with or without drug administration.

Postoperatively, patients were examined in the first 10 days and up to one month following operation by the study team, while further examinations were performed at the Glaucoma Department of the University Eye Clinic or by the medical attendants in the patients' area of residence. Examination included best corrected visual acuity, biomicroscopy, tonometry, fundus and optic nerve head evaluation. Perimetry was performed every 6 months or once a year, depending on the severity of the case, in the University Eye Clinic.

During the RDS, we excluded eyes in both groups with perforation of the anterior chamber and iris prolapse or when it was not possible to locate the Schlemm canal after the superficial scleral flap preparation.

All the ophthalmologists at the follow-up examinations were blinded to the fact that these patients were study patients.

\section{Surgical procedures of "reversed" deep sclerectomy}

The operations in both groups were performed by one of the authors (PK) using retrobulbar anesthesia with a $3.0-3.5 \mathrm{~mL}$ mixture solution, consisting of xylocaine $2 \%$ without adrenaline (1.5-2.0 mL) and naropein $10 \%(1.5 \mathrm{~mL})$.

A 4-0 silk suture was placed to the superior rectus muscle of the operated eye, and then followed dissection of the conjunctiva at the limbus at 12 o'clock and hemostasis of the area using diathermy. An area was then selected between 10 and 2 o'clock, where there were no large perforating veins. A scleral flap of $5 \mathrm{~mm}$ length and $4 \mathrm{~mm}$ width was prepared, based at the limbus and with a thickness of approximately $1 / 3-1 / 2$ and full thickness of the sclera. The preparation of the flap was then extended, reaching $1 \mathrm{~mm}$ away from the stroma of the cornea. Using 1.8-2.0 $\times$ magnification on the surgical microscope, and with the aid of a thin diamond knife, we sought the Schlemm canal, performing, carefully, a radial incision at the limbus. This search took place exactly at the 
limbus, where the white sclera changes into the darker area of the trabeculum. Guiding sign for locating the Schlemm canal was the horizontal white fibers of the sclera spur that lies at the border line of the white sclera. Right in front of these fibers lies the Schlemm canal from which, after perforation, aqueous humor wells up. In certain cases, when the Schlemm canal is filled with blood, this is what wells up after perforation.

Following the location of the Schlemm canal, the radial incision was extended to the opposite side of the quadrangle, so as to divide it into two equal parts. The depth of the incision must not extend to the full thickness of the scleral stroma in order to avoid reaching the ciliary body. Two parallel incisions were then made, on both sides of the above incision, near the oblique sides of the quadrangle, extending towards the limbus only, so as to facilitate the preparation of the anterior part of the deep scleral flap. At this time we perforated the anterior chamber in order to cause hypotony of the eye and thus separate the inner and outer layer of the Schlemm canal. Using very thin Vannas scissors, we excised the outer layer of the Schlemm canal by inserting one leg of the scissors into the canal, from the main opening, first in one and then in the other side. With the aid of a triangular sponge, we detached the anterior segment of the scleral flap from the underlying trabeculum. The detachment in extended beyond Schwalbe I, toward Descement's membrane, which we revealed at an area of about $0.5-1.0 \mathrm{~mm}^{2}$ Using small scissors, we excised this anterior segment of the deep scleral stroma.

The posterior part of the deep scleral stroma was separated with the aid of the diamond knife into 2 parts - petals, leaving a very thin layer of sclera corresponding to the ciliary body. One petal was then prepared up to its middle, while the remainder was undermined in order to fold the latter inside. In the same manner we folded the other petal too. Following the folding of the two petals, a triangular endoscleral space was formed. Next, we sutured the superficial sclera flap, placing two $10-0$ sutures, at the corners of the quadrangle. A small quantity of viscoelastic fluid was placed under the superficial flap. The conjunctiva was sutured at the limbus using two 8-0 sutures.

If, during the preparation of the anterior segment of the deep scleral flap (towards Descement's membrane), a small perforation of the trabeculo-Descement's membrane was to take place, without iris prolapse, we would continue the operation, not taking it into account. If the perforation was greater and the iris prolapsed, then we would perform peripheral iridectomy, and then continue the remainder of the operation without converting it to typical trabeculectomy.

In cases where RDS must be combined with phaco (group B), penetration of the anterior chamber was performed at the same position where the superficial flap of the RDS was prepared, and following the precise location of the Schlemm canal and the two parallel incisions on both sides of the central incision in the deep scleral stroma. Afterwards, followed infusion of the viscoelastic fluid in the anterior chamber, capsulorhexis, hydrodissection, phaco, and aspiration of the remaining cortex. After insertion of the proper, folded intraocular lens, and without removing the viscoelastic fluid from the anterior chamber, followed opening of the Schlemm canal and preparation of the anterior and posterior segment of the deep scleral stroma, as previously described. Prior to suturing the superficial scleral flap, the viscoelastic fluid was removed from the anterior chamber. Finally, the conjunctiva was sutured.

Postoperatively, patients were administered a combination of corticosteroids and antibiotic eye drops, 1-2 drops 3 times daily for a period of three weeks. During the first week, tropixal eye drops, 1-2 drops 3 times daily was added.

If during the follow-up examinations, an encapsulated bleb is formed or signs of fibrosis of the bleb are evident and at the same time elevation of the IOP occurs, we performed subconjunctival injections of 5-fluorouracil (5-FU) $(0.1 \mathrm{~mL}$ of a $50 \mathrm{mg} / \mathrm{mL}$ solution) at 6 o'clock once daily for 5 consecutive days.

The operations were considered by us a "total success" if IOP did not exceed $21 \mathrm{mmHg}(\leq 21 \mathrm{mmHg})$ without administrating glaucoma drugs or without 5-FU subconjunctival injections; a "relative success" if we achieved the same results with the aid of glaucoma drugs and/or 5-FU subconjunctival injections; and a "complete failure" if the IOP exceeded $21 \mathrm{mmHg}$ with drugs and/or 5-FU subconjunctival injections.

\section{Statistical analysis}

Statistical analysis consisted of $\chi^{2}$-test for qualitative parameters and t-test for quantitative parameters.

\section{Results}

A total of 143 eyes were scheduled to undergo RDS or combined phaco-RDS. In 9 of the 143 eyes (6.3\%) occurred penetration of the anterior chamber and iris prolapse ( 3 cases from group A and 6 cases from group B), and were therefore excluded from the study. Two more cases were also excluded because it was not possible to locate the Schlemm canal after preparing the superficial scleral flap. In these two cases, the operation was converted to typical trabeculectomy. On the contrary, we included in the study eyes that during the operation sustained minor penetrations of the anterior chamber without 
iris prolapse. Such minor penetrations were observed in 10 eyes $(7.6 \%) ; 2$ cases from group A and 8 cases from group B. Therefore, the total of the eyes that were included in the study were 132 (37 cases in group A and 95 cases in group B).

The average follow-up time for group A was $22.23 \pm 10.18$ months and for group B was $25.36 \pm 10.12$ months with minimum and maximum follow-up time for both groups being 12 and 45 months, respectively. Table 2 presents the postoperative results of our study. At the time of the last follow-up examination, "total success" was achieved for $40.5 \%(15 / 37)$ of the eyes in group A and for $66.3 \%(63 / 95)$ of the eyes in group B. "Relative success" for group A was $94.6 \%$ (35/37) and 94.7\% (90/95) for group B. For group A, the mean postoperative IOP at the last follow-up examination was $17.46 \pm 4.79 \mathrm{mmHg}$ and the mean decrease in IOP was $7.02 \pm 6.35 \mathrm{mmHg}$, while for group B was $15.73 \pm 2.14 \mathrm{mmHg}$ and $5.26 \pm 3.72 \mathrm{mmHg}$ respectively. Figure 1 represents the fluctuation of the mean postoperative IOP for both groups.

The mean number of glaucoma drugs which were administrated postoperatively for each patient was $1.00 \pm 0.91 \mathrm{drugs}$ for group A and $0.43 \pm 0.66$ for group B, while preoperatively, the mean number of glaucoma drugs administrated was $2.97 \pm 0.69$ and $2.56 \pm 0.73$, respectively (the mean reduction of glaucoma drugs was for group A $1.97 \pm 1.09$ and for group B, $2.14 \pm 0.95$ ) (Table 3).

Injections of 5-FU during follow-up were performed in 8 eyes from group A and 5 eyes from group B. Seven eyes that were characterized as "complete failures" (2 eyes from group A and 5 eyes from group B) underwent a second operation: 6 eyes underwent trabeculectomy using mitomycine- $C$, with satisfying results, and 1 eye underwent Ahmed valve implantation (from group B).

Visual acuity for group A, for most cases, returned to preoperative levels $1-2$ weeks after the operation. In group $\mathrm{B}$, visual acuity reached maximum level 3-4 weeks after the operation.

The presence of pseudoexfoliation in group A as well in group B did not affect the final postoperative IOP, regarding neither the amount of reduction nor the mean number of glaucoma drugs used postoperatively (Table 4). The only difference noted, was that the mean age of the patients with pseudoexfoliation was greater than those without.

Regarding the size of the bleb, we never noted enlarged blebs with cyst formation, or complications regarding prolonged hypotony of the bulb, or inflammation during follow-up. Increase in IOP during the first or second month, postoperatively, which could be attributed to an encapsulated bleb, was dealt with 5-FU injections subconjunctively (8 cases from group A and 5 cases from group B) (Table 2).

Goniopuncture was not applied in any case.

Regarding complications, in 5 eyes from group A we noted swallowing of the anterior chamber, accompanied by hypotony of the bulb that lasted 1-7 days (in 2 of these cases occurred small rupture of the trabeculo-Descement's diaphragm without iris prolapse). In 2 other cases, we noted leakage of aqueous humor from the conjunctival incision at the limbus (Seidel sign). In the first case we had to place two 8-0 sutures, while in the second one spontaneous occlusion occurred 2-3 days later with pressure dressing of the eye. No other complication was noted. In group B we noted relative swallowing of the anterior chamber for a period of $1-2$ days in 2 eyes, small hyphema $(0.5-1.0 \mathrm{~mm})$ in 5 eyes, choroidal detachment in 1 eye, and leakage of aqueous humor from the conjunctival incision at the limbus (Seidel sign) in 1 eye. In all cases spontaneous cure occurred.

In eyes with total and relative success at follow-up, the progression of optic nerve damage and visual field defects were stable in both groups.

\section{Discussion}

RDS is a classic DS which, after the formation of the superficial scleral flap, we open first the Schlemm canal, and then the anterior part of the deep scleral stroma is prepared and excised, while the posterior part follows, in the manner that was already described in detail in the Materials and methods section. Locating and opening the Schlemm canal

Table 2 Postoperative results (I 32 eyes of I I 4 patients)

\begin{tabular}{|c|c|c|}
\hline & Group A (37 eyes) & Group B (95 eyes) \\
\hline Total success & I 5/37 (40.5\%) & $63 / 95(66.3 \%)$ \\
\hline Relative success & $35 / 37(94.6 \%)$ & $90 / 95(94.7 \%)$ \\
\hline Complete failure & $2 / 37(5.4 \%)$ & $5 / 95(5.3 \%)$ \\
\hline Postoperative IOP (mmHg), mean (SD) & $17.46(4.79)$ & $15.73(2.14)$ \\
\hline IOP decrease (mmHg), mean (SD) & $7.02(6.35)(28.67 \%)$ & $5.26(3.72)(25.06 \%)$ \\
\hline Number of antiglaucoma drugs postoperatively, mean (SD) & $\mathrm{I} .0(0.9 \mathrm{I})$ & $0.43(0.66)$ \\
\hline Decrease in number of antiglaucoma drugs, mean (SD) & $1.97(1.09)$ & $2.14(0.95)$ \\
\hline Use of 5-FU (number of eyes) & $8(21.60 \%)$ & $5(5.3 \%)$ \\
\hline
\end{tabular}




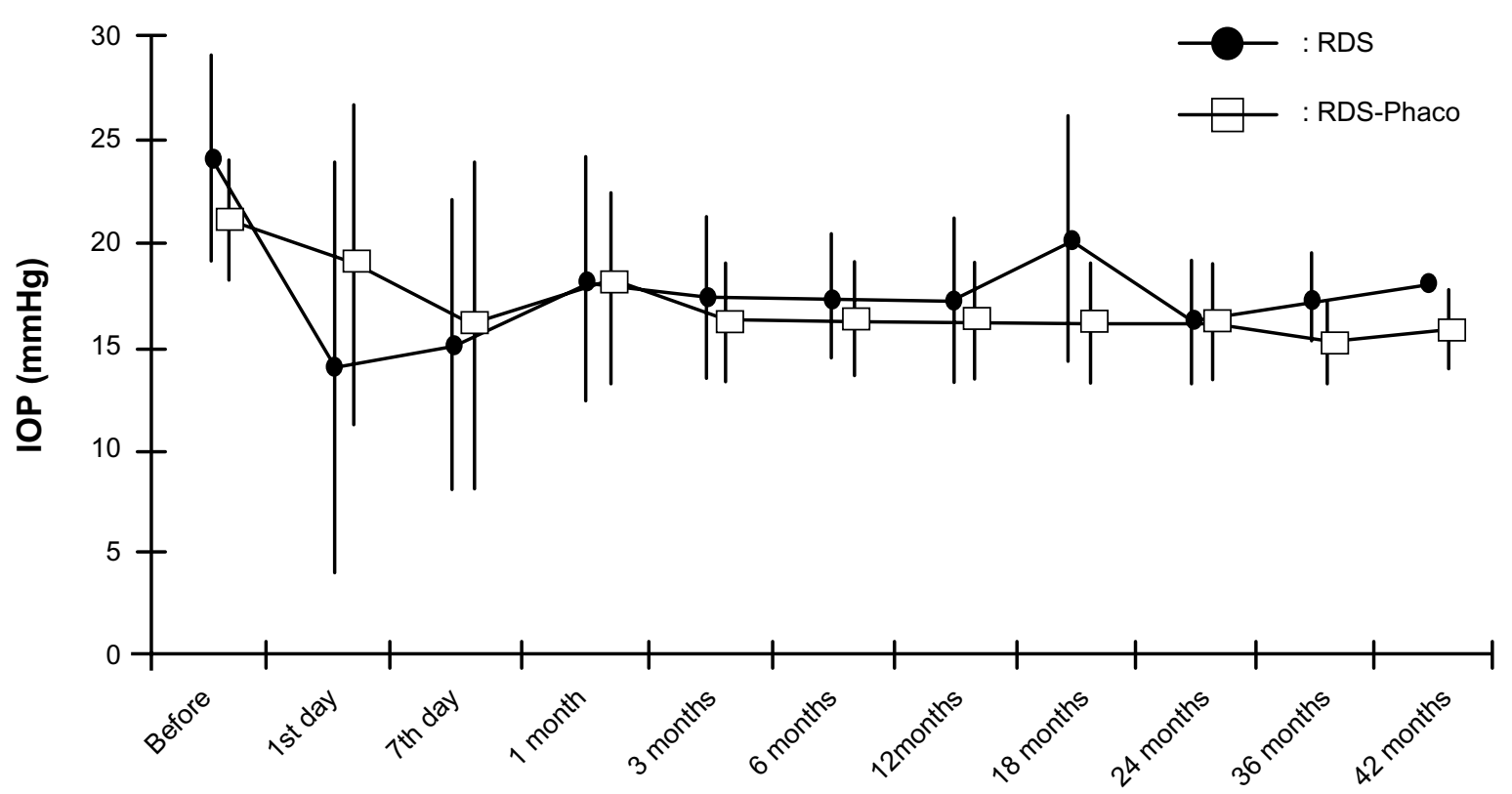

Time

Figure I Fluctuation of mean postoperative IOP for both groups.

Abbreviations: RDS, "reversed" deep sclerectomy; phaco, phacoemulsification.

becomes relatively easy after only a few cases (only in 2 out of the total cases were we unable to locate the Schlemm canal). Locating it is even easier for surgeons that know how to perform trabeculectomy "ab externo" of Harms and Danheim. ${ }^{43}$

Executing RDS in the manner described ensures certain location of the Schlemm canal, not risking entering the anterior chamber, while preparing the deep scleral flap and approaching the Schlemm canal. Karlen et al ${ }^{19}$ report perforation of the anterior chamber and iris prolapse in $30 \%$ of cases for the first 10 operations performed. Likewise, Dahan and Drusedau ${ }^{22}$ report perforation of the anterior chamber in 1 out of 3 operations during the first 6 months of performing DS.

As one may notice, in our method of operation the inner wall of the Schlemm canal is not removed. Some surgeons while performing DS, with or without the use of implant, remove the inner wall of the Schlemm canal, along with the juxtacanalicular trabeculum,,${ }^{4,622,44}$ while others like Mermoud's team do not. ${ }^{9,11-13,19,23,40,45-47}$ Folding and not excising part of the deep scleral stroma, in our opinion, enforces the depth of the endoscleral space or parathalamus. ${ }^{48,49} \mathrm{We}$ do not use an implant, but we infuse a small quantity of viscoelastic fluid under the superficial scleral flap after suturing it. To facilitate the opening of the Schlemm canal, we tap the anterior chamber in order to cause hypotony of the orbit and thus avoid collapsing of the walls of the Schlemm canal. The same operation is performed by Stegmann, before he opens the Schlemm canal, during viscocanalostomy. ${ }^{3} \mathrm{We}$, as well as he, did not notice any case of malignant glaucoma after tapping the anterior chamber and causing hypotony of the bulb.

The postoperative results ("total success", "relative success", "complete failure") from group A are comparable to classic DS with or without implant, with the same or longer follow-up time, even though comparing the results of different

Table 3 Tonometry data and antiglaucoma drug treatment (preoperatively and postoperatively)

\begin{tabular}{|c|c|c|c|}
\hline & Preoperative & Postoperative & $P$ value \\
\hline \multicolumn{4}{|l|}{ Group A } \\
\hline IOP (mmHg), mean (SD) & $24.48(4.93)$ & I7.46 (4.79) & $<0.05$ \\
\hline Decrease IOP $(\mathrm{mmHg})$, mean (SD) & \multicolumn{2}{|c|}{$7.02(6.35)(28.67 \%)$} & \\
\hline Number of antiglaucoma drugs, mean (SD) & $2.97(0.69)$ & $1.0(0.91)$ & $<0.01$ \\
\hline \multicolumn{4}{|l|}{ Group B } \\
\hline IOP $(\mathrm{mmHg})$, mean $(\mathrm{SD})$ & $20.99(3.30)$ & $15.73(2.14)$ & $<0.05$ \\
\hline Decrease IOP (mmHg), mean (SD) & \multicolumn{2}{|c|}{$5.26(3.72)(25.06 \%)$} & \\
\hline Number of antiglaucoma drugs, mean (SD) & $2.56(0.73)$ & $0.43(0.66)$ & $<0.01$ \\
\hline
\end{tabular}


Table 4 Effect of pseudoexfoliation on postoperative IOP

\begin{tabular}{llll}
\hline & Pseudoexfoliation (-) & Pseudoexfoliation (+) & P value \\
\hline Group A (37 eyes) & & & \\
Number of eyes & $28(75.7 \%)$ & $9(24.3 \%)$ \\
Age (years), mean (SD) & $67.79(8.19)$ & $75.67(6.28)$ & $<.73(4.5 I)$ \\
Decrease IOP (mmHg) postoperative, mean (SD) & $7.75(6.75)$ & $1.33(1.22)$ & $\mathrm{NS}$ \\
Number of antiglaucoma drugs pre-postoperative, mean (SD) & $2.18(0.98)$ & & $\mathrm{N}$ \\
Group B (95 eyes) & & $31(32.6 \%)$ \\
Number of eyes & $64(67.4 \%)$ & $77.97(6.06)$ & $5.89(4.13)$ \\
Age (years), mean (SD) & $72.0(7.9)$ & $2.03(0.98)$ & $\mathrm{NS}$ \\
Decrease IOP (mmHg) postoperative, mean (SD) & $4.95(3.5)$ & $2.19(0.93)$ & $\mathrm{NS}$ \\
Number of antiglaucoma drugs pre-postoperative, mean (SD) & &
\end{tabular}

studies is difficult. Therefore, some authors ${ }^{5,9,13,19,23,40,46,47}$ report complete success in $40 \%-70 \%$ of their cases and relative success in $85.0 \%-97.7 \% 0^{5,9,19,23,40,47}$ with mean postoperative reduction of IOP at $25 \%-50 \%$. $^{9,13,23,40,46,47}$

The postoperative success in group B is relatively higher than previous studies. Gianoli et $\mathrm{al}^{12}$ report $81 \%$ relative success in a period of 18 months in a series of 60 eyes that underwent a combined operation of phaco and DS. D'Eliseo et $\mathrm{al}^{50}$ report, following combined operation of phaco and DS, a success rate of $90 \%$, without the use of glaucoma drugs, and mean IOP postoperatively of $13.1 \mathrm{mmHg}$. The relatively higher success rate in our cases $(94.7 \%)$ can be attributed, in our opinion, partly to the fact that 56 out of 95 eyes (59\%) with glaucoma and cataract that were included in our study and were operated with combined operation of phaco and RDS, had preoperatively IOP $<21 \mathrm{mmHg}$ while taking glaucoma medication.

Shaarawy et $\mathrm{al}^{47}$ used 5-FU in 21 of 52 cases that underwent DS with the use of implant. Gianoli et al ${ }^{12}$ used 5-FU in 5 of 30 cases that underwent combined operation of phaco and DS.

Postoperative complications were few and insignificant for the outcome of the operations. The postoperative complications observed with our technique of DS are not more or greater than those of the classic technique of DS. $5,9,11,13,15,19,23,40,47$

In conclusion, we can claim that the suggested RDS is a classic DS, where the removal of the deep scleral stroma is performed reversely, meaning first, the segment anterior to the Schlemm canal is excised, and then the segment posterior to the canal, in two parts, are folded. That way, we always ensure opening of the Schlemm canal, and with the folding of the two parts of the posterior segment of the deep scleral flap the parathalamus is enforced, without the use of special implants.

Our postoperative results of RDS in both groups (RDS or combined phaco-RDS), do not fall behind those of the classic DS according to previous studies. Furthermore postoperative complications are no more or greater, while in our opinion, the learning curve of this technique is far shorter than that of the classic DS.

\section{Disclosure}

The authors report no conflicts of interest. The authors alone are responsible for the content and writing of the paper.

\section{References}

1. Kozlov VI, Bagrov SN, Anisimova SY, et al. [Deep sclerectomy with collagen]. Eye Microsurgery. 1990;3:44-46. [in Russian]

2. Fyodorov SN, Ioffe DI, Ronkina TI. Deep sclerectomy: technique and mechanism of a new glaucoma procedure. J Glaucoma. 1984;6: 281-283.

3. Stegmann R, Pienaar A, Miller D. Viscocanalostomy for open-angle glaucoma in black African patients. J Cataract Refract Surg. 1999; 25:316-322.

4. Hamard P, Plaza L, Kopel J, Quesnot S, Hamard H. [Deep nonpenetrating sclerectomy and open angle glaucoma. Intermediate results from the first operated patients]. J Fr Ophtalmol. 1999;22:25-31. French.

5. Demailly P, Jeanteur-Lunel MN, Berkani M, et al. [Non-penetrating deep sclerectomy combined with a collagen implant in primary openangle glaucoma. Medium-term retrospective results]. J Fr Ophtalmol. 1996;19:659-666. [in French]

6. Sourdille P, Santiago PY, Villain F, et al. Reticulated hyaluronic acid implant in nonperforating trabecular surgery. JCataract Refract Surg. 1999; 25:332-339.

7. Kozobolis VP, Christodoulakis EV, Tzanakis N, Zacharopoulos I, Pallikaris IG. Primary deep sclerectomy versus primary deep sclerectomy with the use of mitomycin $\mathrm{C}$ in primary open-angle glaucoma. J Glaucoma. 2002;11:287-293.

8. Zimmerman TJ, Kooner KS, Ford VJ, et al. Trabeculectomy vs nonpenetrating trabeculectomy: a retrospective study of two procedures in phakic patients with glaucoma. Ophthalmic Surg. 1984;15:734-740.

9. Mendrinos E, Mermoud A, Shaarawy T. Nonpenetrating glaucoma surgery. Surv Ophthalmol. 2008;53:592-630.

10. Johnson MC, Kamm RD. The role of Schlemm's canal in aqueous outflow from the human eye. Invest Ophthalmol Vis Sci. 1983;24:320-325.

11. Mermoud A, Schnyder CC, Sickenberg M, Chiou AG, Hédiguer SE, Faggioni R. Comparison of deep sclerectomy with collagen implant and trabeculectomy in open-angle glaucoma. J Cataract Refract Surg. 1999;25:323-331.

12. Gianoli F, Schnyder CC, Bovey E, Mermoud A. Combined surgery for cataract and glaucoma: phacoemulsification and deep sclerectomy compared with phacoemulsification and trabeculectomy. $J$ Cataract Refract Surg. 1999;25:340-346.

13. Chiselita D. Non - penetrating deep sclerectomy versus trabeculectomy in primary open-angle glaucoma surgery. Eye (Lond). 2001;15(Pt 2): 197-201. 
14. Sanchez E, Schnyder CC, Sickenberg M, Chiou AG, Hédiguer SE, Mermoud A. Deep sclerectomy: results with and without collagen implant. Int Ophthalmol. 1996-1997;20(1-3):157-162.

15. El Sayyad F, Helal M, El-Kholify H, Khalil M, El-Maghraby A. Nonpenetrating deep sclerectomy versus trabeculectomy in bilateral primary open-angle glaucoma. Ophthalmology. 2000;107:1671-1674.

16. Netland PA; for Ophthalmic Technology Assessment Committee Glaucoma Panel, American Academy of Ophthalmology. Nonpenetrating glaucoma surgery. Ophthalmology. 2001;108:416-421.

17. Watson PG, Jakeman C, Ozturk M, Barnett MF, Barnett F, Khaw KT. The complications of trabeculectomy (a 20-year follow-up). Eye (Lond). 1990;4(Pt 3):425-438

18. Glaucoma: American Academy of Ophthalmology. The Eye MD Association. Lifelong education for the ophthalmologist, section 10. 2008-2009;8:211-217.

19. Karlen ME, Sanchez E, Schnyder CC, Sickenberg M, Mermoud A. Deep sclerectomy with collagen implant: medium term results. BrJOphthalmol. 1999;83:6-11.

20. Bas JM, Goethals MJ. Non-penetrating deep sclerectomy preliminary results. Bull Soc Belge Ophtalmol. 1999;272:55-59.

21. Banchiero L, Demarie A, Belli L, Brogliatti B. Deep sclerectomy and viscocanalostomy: critical revision of the results obtained during the learning curve. Acta Ophthalmol. Scand, Suppl. 2002;236:64-66.

22. Dahan E, Drusedau MU. Nonpenetrating filtration surgery for glaucoma: control by surgery only. J Cataract Refract Surg. 2000;26:695-701.

23. Cheng JW, Xi GL, Wei RL, Cai JP, Li Y. Efficacy and tolerability of nonpenetrating filtering surgery in the treatment of open-angle glaucoma: a meta-analysis. Ophthalmologica. 2009;224:138-146.

24. Mendrinos E, Mansouri K, Mermoud A, Shaarawy T. Long-term results of deep sclerectomy with collagen implant in exfoliative glaucoma. J Glaucoma. 2009;18:361-367.

25. Mansouri K, Tran HV, Ravinet E, Mermoud A. Comparing deep sclerectomy with collagen implant to the new method of very deep sclerectomy with collagen implant: a single-masked randomized controlled trial. J Glaucoma. 2010;19:24-30.

26. Chihara E, Okazaki K, Takahashi H, Shoji T, Adachi H, Hayashi K. Modified deep sclerectomy (D-lectomy MMC) for primary open-angle glaucoma: preliminary results. J Glaucoma. 2009;18:132-139.

27. Muñoz G. Nonstitch suprachoroidal technique for T - flux implantation in deep sclerectomy. J Glaucoma. 2009;18:262-264.

28. Godfrey DG, Fellman RL, Neelakantan A. Canal surgery in adult glaucomas. Curr Opin Ophthalmol. 2009;20:116-121.

29. Bissig A, Rivier D, Zaninetti M, Shaarawy T, Mermoud A, Roy S. Ten years follow-up after deep sclerectomy with collagen implant. $J$ Glaucoma. 2008; 17:680-686.

30. Galassi F, Giambene B. Deep sclerectomy with SkGel implant: 5-year results. J Glaucoma. 2008;17:52-56.

31. Leszczyński R, Gierek-Ciaciura S, Forminśka-Kapuścik M, Mrukwa-Kominek E, Rokita-Wala I. Nonpenetrating very deep sclerectomy with reticulated hyaluronic acid implant in glaucoma treatment. Med Sci Monit. 2008;14:CR86-CR89.
32. Cillino S, Di Pace F, Casuccio A, Cillino G, Lodato G. Deep sclerectomy versus trabeculectomy with low - dosage mitomycin C: four-year follow-up. Ophthalmologica. 2008;222:81-87.

33. Russo V, Scott IU, Stella A, et al. Nonpenetrating deep sclerectomy with reticulated hyaluronic acid implant versus punch trabeculectomy: a prospective clinical trial. Eur J Ophthalmol. 2008;18(5):751-757.

34. Carassa RG. Surgical alternative to trabeculectomy. Prog Brain Res. 2008; 173:255-261.

35. Kotliar KE, Kozlova TV, Lanzl IM. Postoperative aqueous outflow in the human eye after glaucoma filtration surgery: biofluidmechanical considerations. Biomed Tech (Berl). 2009;54:14-22.

36. Grehn F. [Surgery of primary open angle glaucoma]. Klin Monbl Augenheilkd. 2008;225:30-38. Review. German.

37. Vizzeri G, Weinreb RN. Cataract surgery and glaucoma. Curr Opin Ophthalmol. 2010;21:20-24.

38. Yuen NS. Early results of modified nonpenetrating deep sclerectomy and phacoemulsification in the treatment of open angle glaucoma and cataract. Eur J Ophthalmol. 2009;19:72-79.

39. Anand S, Anand N. Combined phacoemulsification and deep sclerectomy (PDS) with intraoperative mitomycin C (MMC) augmentation. Eye (Lond). 2008;22:1040-1049.

40. Baudouin C, Hamard P, Labbé A. [Surgical key points. Nonpenetrating sclerectomy]. J Fr Ophtalmol. 2007;30(5 Pt 2):3S52-57. Review. French.

41. Psilas K, Aspiotis M, Kitsos G, Eftaxias V, Psylla MK. The reversed deep sclerectomy in the treatment of the chronic open-angle glaucoma. XX Congress of the ESCRS; Nice, FRANCE, 2002. Abstract page 106.

42. Glaucoma: American Academy of Ophthalmology. The Eye MD Association. Lifelong education for the ophthalmologist, section 10. 2008-2009;1:3-16 and 4:85-121.

43. Harms H, Dannheim R. Trabeculotomy - results and problems. Bibl Ophthalmol. 1970;81:121-131.

44. Hamard P, Valtot F, Sourdille P, Bourles-Dagonet F, Baudouin C. Confocal microscopic examination of trabecular meshwork removed during ab externo trabeculectomy. Br J Ophthalmol. 2002;86:1046-1052.

45. Chiou AG, Mermoud A, Underdahl JP, Schnyder CC. An ultrasound biomicroscopic study of eyes after deep sclerectomy with collagen implant. Ophthalmology. 1998;105:746-750.

46. Ambresin A, Shaarawy T, Mermoud A. Deep sclerectomy with collagen implant in one eye compared with trabeculectomy in the other eye of the same patient. J Glaucoma. 2002;11:214-220.

47. Shaarawy T, Nguyen C, Schnyder C, Mermoud A. Comparative study between deep sclerectomy with and without collagen implant: long term follow up. Br J Ophthalmol. 2004;88:95-98.

48. Lambrou N, Fronimopoulos J. [The role of the parathalamus in covered sclerectomy]. Klin Monbl Augenheilkd. 1984;184:259-260. German.

49. Lambrou N, Fronimopoulos J. [The significance of the scleral flap for the surgery of glaucoma (author's transl)]. Klin Monbl Augenheilkd. 1978;173:599-606. [in German]

50. D'Eliseo D, Pastena B, Longanesi L, Grisanti F, Negrini V. Comparison of deep sclerectomy with implant and combined glaucoma surgery. Ophthalmologica. 2003;217:208-211.
Clinical Ophthalmology

\section{Publish your work in this journal}

Clinical Ophthalmology is an international, peer-reviewed journal covering all subspecialties within ophthalmology. Key topics include: Optometry; Visual science; Pharmacology and drug therapy in eye diseases; Basic Sciences; Primary and Secondary eye care; Patient Safety and Quality of Care Improvements. This journal is indexed on Submit your manuscript here: http://www.dovepress.com/clinical-ophthalmology-journal

\section{Dovepress}

PubMed Central and CAS, and is the official journal of The Society of Clinical Ophthalmology (SCO). The manuscript management system is completely online and includes a very quick and fair peer-review system, which is all easy to use. Visit http://www.dovepress.com/ testimonials.php to read real quotes from published authors. 